\title{
LDRD Final Report for 01-ERD-100 \\ FLIRT: A magnetic field topology diagnostic for spheromaks and other self- organized magnetically confined plasmas
}

H.S. McLean, H. Chen, D.D. Ryutov

January 23, 2003

U.S. Department of Energy

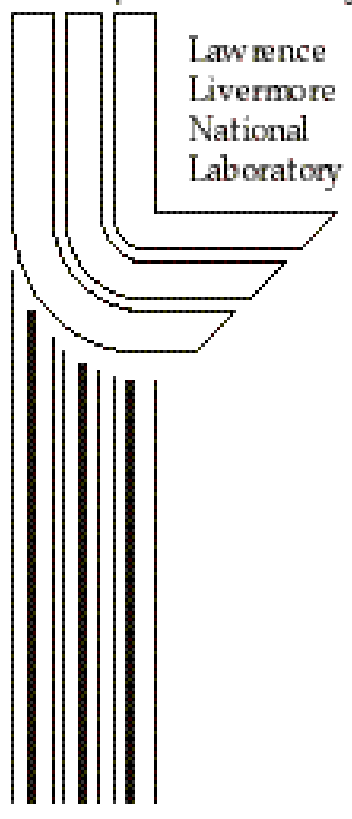




\section{DISCLATMER}

This document was prepared as an account of work sponsored by an agency of the United States Government. Neither the United States Government nor the University of California nor any of their employees, makes any warranty, express or implied, or assumes any legal liability or responsibility for the accuracy, completeness, or usefulness of any information, apparatus, product, or process disclosed, or represents that its use would not infringe privately owned rights. Reference herein to any specific commercial product, process, or service by trade name, trademark, manufacturer, or otherwise, does not necessarily constitute or imply its endorsement, recommendation, or favoring by the United States Government or the University of California. The views and opinions of authors expressed herein do not necessarily state or reflect those of the United States Government or the University of California, and shall not be used for advertising or product endorsement purposes.

This work was performed under the auspices of the U.S. Department of Energy by the University of California, Lawrence Livermore National Laboratory under Contract No. W-7405-Eng-48.

This report has been reproduced directly from the best available copy.

Available for a processing fee to U.S. Department of Energy

and its contractors in paper from

U.S. Department of Energy

Office of Scientific and Technical Information

$$
\text { P.O. Box } 62
$$

Oak Ridge, TN 37831-0062

Telephone: (865) 576-8401

Facsimile: (865) 576-5728

E-mail: reports@adonis.osti.gov

Available for the sale to the public from

U.S. Department of Commerce

National Technical Information Service

5285 Port Royal Road

Springfield, VA 22161

Telephone: (800) 553-6847

Facsimile: (703) 605-6900

E-mail: orders@ntis.fedworld.gov

Online ordering: http://www.ntis.gov/ordering.htm

OR

Lawrence Livermore National Laboratory

Technical Information Department's Digital Library

http://www.llnl.gov/tid/Library.html 


\section{LDRD Final Report for 01-ERD-100 \\ FLIRT: A magnetic field topology diagnostic for spheromaks and other self-organized magnetically confined plasmas. \\ H.S. McLean, H. Chen, D.D. Ryutov \\ Lawrence Livermore National Laboratory.}

\section{Introduction}

Tangled magnetic field lines are common in laboratory and space plasmas, but determining the geometrical structure of magnetic fields in the presence of plasma is a difficult and still unresolved problem. To address this open question we developed and tested a new technique for measuring the magnetic field-line topology in magnetically confined plasmas. Our field-line tracing diagnostic (FLIRT) uses a high-power, short-pulse laser to launch a burst of energetic $(\sim 100 \mathrm{keV})$ electrons from a target passing through the plasma. These electrons then generally follow magnetic-field lines until they strike a solid surface, where a burst of x-rays is produced. The field-line connection length can be determined from the time delay between the laser pulse and the burst of x-rays. The topology of the field lines can be inferred by measuring the connection length as a function of initial target location inside the plasma. Measuring the spatial distribution of $\mathrm{x}$-ray production provides further information on the field topology, including the effects of magnetic field fluctuations and stochasticity.

The goals of this experiment were to test the appropriate x-ray detectors; measure the background x-ray emission in a spheromak plasma; measure the energetic electron production by a short-pulse, high-power laser; make preliminary measurements of the edge field line topology in the Sustained Spheromak Physics Experiment (SSPX), and perform analytic studies of electron production. These results are reported in detail in three publications listed below. A brief summary follows.

\section{Publications}

1. H. McLean, et al., UCRL-JC-149196 "A laser-based diagnostic for tracing magnetic field lines in spheromaks and other self-organized magnetically confined plasmas," to be published in Review of Scientific Instruments, March 2003.

2. H. Chen, et al., UCRL-JC-149724 "A novel compact electron spectrometer for hot electron measurement in pulsed laser solid interaction," to be published in Review of Scientific Instruments, March 2003.

3. D. Ryutov, UCRL-JC-144196 "Space Charge effects in the emission of fast electrons generated by a short laser pulse," submitted to Lasers and Particle Beams, June 2001.

\section{Summary of results:}

The results are separated in three parts and correspond to the papers submitted for publication: plasma x-ray and electron measurements, electron production with a high power laser, and analytic studies of electron production and dynamics. 


\section{Plasma x-ray and electron measurements.}

The results (1) confirmed that background plasma x-rays in SSPX will not interfere with the expected x-ray signals; (2) demonstrated an electron gun system that produces the pulse width ( $10 \mathrm{~ns})$ and energy spectrum (10-100 keV) necessary to simulate the laser-produced electrons; and (3) tested a fast detection system that can easily resolve line lengths of $<0.70 \mathrm{~m}$. Tests on SSPX injecting electrons into a plasma showed further work was required in separating the $\mathrm{x}$-ray pulse generated by the electron gun from X-rays generated by electrons hitting the walls of the device. No x-rays could be detected after the initial pulse from the gun indicating field line lengths of less than a few meters in the edge. This does not rule out longer field lines in the center of the plasma.

\section{Electron production with high-powered laser.}

We constructed an electron spectrometer and performed detailed measurements of electron production with the JanUSP laser. As expected, we found that the electron energy distribution is broad with average electron energy from $150 \mathrm{keV}$ to $220 \mathrm{keV}$ for laser intensities of $1 \mathrm{e} 18$ to $1 \mathrm{e} 19 \mathrm{~W} / \mathrm{cm}^{\wedge} 2$, respectively. A modest laser energy of $100 \mathrm{~mJ}$ produced $3 \mathrm{e} 11$ electrons at $1 \mathrm{e} 19 \mathrm{~W} / \mathrm{cm}^{\wedge} 2$ giving a conversion efficiency of $\sim 10 \%$. This low energy $(100 \mathrm{~mJ})$ reduces the costs of a fielded system significantly.

\section{Analytic studies of electron production and dynamics.}

A theory of space-charge effects in the emission of fast electrons from the surface was developed which showed that the electron yield depends on the pulse-width and energy of fast electrons, but not on the focal spot size and that the yield could be increase by a factor of ten by using a neutralizing plasma plume.

The lack of large background x-rays signals in SSPX was supported by analytical calculations showing that high-energy $(>100 \mathrm{keV})$ runaway electrons can be formed only if very long flux tubes exist, making at least 5000 turns around the geometrical axis. 3-D magnetohydrodynamic computer simulations showed such conditions are met only sporadically in SSPX, and high-energy X-rays will have a character of short bursts, leaving long "quiet" intervals suitable for the FLIRT measurements. Another analytical study predicted the characteristic shapes of the X-ray pulsed produced by mirror-trapped electrons, electron injected on the rational flux surfaces, and untrapped electrons injected on the open field lines. The role of electron drift and field line stochasticity was also evaluated. 